\title{
Enhancement of differentiation induction and upregulation of CCAAT/enhancer-binding proteins and PU.1 in NB4 cells treated with combination of ATRA and valproic acid
}

\author{
NORIYOSHI IRIYAMA $^{1 *}$, BO YUAN ${ }^{2,4^{*}}$, YUTA YOSHINO $^{2}$, YOSHIHIRO HATTA $^{1}$, AKIRA HORIKOSHI $^{1}$, \\ SHIN AIZAWA ${ }^{3}$, MASAMI TAKEI $^{1}$, JIN TAKEUCHI $^{1}$, NORIO TAKAGI $^{4}$ and HIROO TOYODA ${ }^{2}$ \\ ${ }^{1}$ Department of Hematology and Rheumatology, Nihon University School of Medicine, Itabashi Hospital, Itabashi-ku, \\ Tokyo 173-8610; ${ }^{2}$ Department of Clinical Molecular Genetics, School of Pharmacy, Tokyo University of Pharmacy and \\ Life Sciences, Hachioji, Tokyo 192-0392; ${ }^{3}$ Department of Functional Morphology, Nihon University School of Medicine, \\ Itabashi-ku, Tokyo 173-8610; ${ }^{4}$ Department of Applied Biochemistry, School of Pharmacy, \\ Tokyo University of Pharmacy and Life Sciences, Hachioji, Tokyo 192-0392, Japan
}

Received November 2, 2013; Accepted December 2, 2013

DOI: $10.3892 /$ ijo.2013.2236

\begin{abstract}
The effects of all-trans retinoic acid (ATRA) and valproic acid (VPA), alone and in combination, on the human acute promyelocytic leukemia (APL) cell line NB4 were investigated in view of differentiation induction and growth inhibition. After $48 \mathrm{~h}$ of treatment, not only ATRA but also VPA induced differentiation in NB4 cells, and their combination further augmented the differentiation activity. Furthermore, the upregulation of transcription factors including CCAAT/enhancer-binding proteins $(\mathrm{CEBP} \alpha, \beta, \varepsilon)$ and PU.1, which are known to be critical factors for normal myelopoiesis, granulocytic maturation and being repressed in APL, concurred with the differentiation induction. A significant cell growth inhibition was observed after the treatment with VPA, which was further strengthened by the addition of ATRA. Given the importance of C/EBPs and PU.1 in myeloid development, these results, thus, suggest that restoration of the normal function of the myeloid cell transcriptional machinery is a major molecular mechanism underlying the differentiation induction in NB4. Therefore, these results may provide novel insights into a possible combinational therapeutic approach for APL patients.
\end{abstract}

Correspondence to: Dr Bo Yuan, Department of Clinical Molecular Genetics, Tokyo University of Pharmacy and Life Sciences, 1432-1 Horinouchi, Hachioji, Tokyo 192-0392, Japan

E-mail: yuanbo@toyaku.ac.jp

"Contributed equally

Key words: all-trans retinoic acid, valproic acid, CCAAT/enhancerbinding proteins, acute promyelocytic leukemia, differentiation, PU.1, NB4

\section{Introduction}

The majority of acute promyelocytic leukemia (APL) patients harbor the $t(15 ; 17)$ translocation leading to the expression of the fusion protein promyelocytic leukemia-retinoic acid receptor $\alpha$ (PML-RAR $\alpha)(1,2)$. The oncogenic fusion protein PML-RAR $\alpha$ can recruit corepressor (CoR) complexes containing nuclear receptor CoR, histone deacetylases (HDACs), resulting in myeloid differentiation arrest observed in APL $(3,4)$. All-trans retinoic acid (ATRA) induces differentiation of APL cells through not only dissociating CoR from PML-RAR $\alpha$ oncoprotein, but also recruiting coactivators that possess histone acetylase activity (3-5). Due to its good clinical outcomes, ATRA is used as a first-line administration for de novo APL patients. Nevertheless, an approximately $30 \%$ of the patients relapse and often become resistant to the conventional treatment (6).

Recent clinical studies have demonstrated that following remission induction with arsenic trioxide (ATO)-based regimens in patients with relapsed APL, consolidation with autologous stem cell transplantation (SCT) is associated with a significantly superior clinical outcome as compared with other maintenance regimens $(7,8)$. However, relapsed APL patients ineligible for autologous SCT usually have poor prognosis (8). Therefore, it would be logical to consider more efficacious treatment strategy employing ATRA in combination with other drugs to cure the disease in the initial treatment. Since HDACs play a key role in transcriptional regulation and pathogenesis of cancer $(9,10)$, its inhibitors (HDACi) are currently being developed for therapy of several types of cancer including leukemia (11). Valproic acid (VPA) belongs to the class I HDACi and shows potential anti-leukemic activities either alone or in combination with other anti-leukemic agents $(9,10,12,13)$. Furthermore, aberrant recruitment of HDACs through expression of PML-RAR $\alpha$ has been implicated as an initiating tumorigenic event in APL (3-5). Therefore, there is a logical rationale for use of 
HDACi such as VPA in combination with ATRA in the initial treatment of APL. However, the efficacy of the combination therapy has been investigated mostly in non-APL AML and myelodysplastic syndromes (MDS) (10,13-15), and remains largely unexplored in APL.

Transcription factors, including members of CCAAT/ enhancer-binding proteins (C/EBPs) and PU.1, are critical for normal myelopoiesis, granulocytic maturation and being repressed in APL (4,16-21). Although a number of studies have been conducted to explore the molecular mechanism underlying the effects of ATRA on these transcription factors associated with differentiation induction $(16,18,19,22)$, the effects of VPA alone or in combination with ATRA on human APL cell line harboring PML-RAR $\alpha$ remain largely unclear.

In the current study, the effects of ATRA and VPA, alone and in combination, were investigated by focusing on differentiation and cell viability in the APL cell line NB4 (PML-RAR $\alpha$ positive). The expression profiles of transcription factors, $\mathrm{C} / \mathrm{EBP}(\alpha, \beta, \varepsilon)$ and PU.1 were further evaluated in the cells after treatment with ATRA and VPA.

\section{Materials and methods}

Reagents. ATRA was purchased from Sigma (St. Louis, MO, USA) and dissolved in ethanol to obtain a final concentration of $2 \mathrm{mM}$ and stored at $-20^{\circ} \mathrm{C}$ in the dark. The vehicle reagent, ethanol (final concentration $<0.05 \%$ ), did not affect cell viability and differentiation. VPA was purchased from Wako Pure Chemical Industries (Miyazaki, Japan) and dissolved in phosphate-buffered saline (PBS) to obtain a final concentration of $1 \mathrm{M}$, sterilized by filtration ( $0.22 \mu \mathrm{M}$ filter), and used as the stock solution. Primary antibodies [phycoerythrin (PE)-conjugated mouse anti-human CD11b IgG, fluorescein isothiocyanate (FITC)-conjugated mouse anti-human CD10 IgG], and control antibodies [non-binding mouse IgG-PE isotype antibody and non-binding mouse IgG-FITC isotype antibody] were obtained from BD Transduction Laboratories (San Diego, CA, USA) and were used for assessment of differentiation induction. Rabbit polyclonal antibodies against human $\mathrm{C} / \mathrm{EBP} \alpha, \mathrm{C} / \mathrm{EBP} \beta$, $\mathrm{C} / \mathrm{EBP} \varepsilon$ and PU.1 were purchased from Abnova (Taipei, Taiwan). FITC-conjugated goat anti-rabbit polyclonal IgG secondary antibody was obtained from Kirkegaard and Perry Laboratories (Gaithersburg, MD, USA).

Cell culture and treatment. NB4, a human APL cell line with $\mathrm{t}(15 ; 17)$, was purchased from Deutsche Sammalung von Mikroorganismen und Zellkulturen $\mathrm{GmbH}$ (Braunschweig, Germany) and cultured in RPMI-1640 medium (Sigma, St. Louis, MO, USA) supplemented with $10 \%$ heat-inactivated fetal bovine serum (FBS) (Gibco-BRL, Rockville, MD, USA), $100 \mathrm{U} / \mathrm{ml}$ penicillin, and $100 \mu \mathrm{g} / \mathrm{ml}$ streptomycin (Gibco-BRL, Gaithersburg, MD, USA) at $37^{\circ} \mathrm{C}$ in a humidified atmosphere $\left(5 \% \mathrm{CO}_{2}\right.$ in air). Cells were seeded at a density of $1 \times 10^{5}$ cells $/ \mathrm{ml}$ and treated with $1 \mu \mathrm{M}$ ATRA and various concentrations of VPA $(0.1,0.3,1,3,10 \mathrm{mM})$, alone or in combination.

Trypan blue exclusion assay. After the treatment with ATRA and/or VPA, cell viability of NB4 cells was investigated by trypan blue exclusion assay. Trypan blue negative and positive cells were considered as viable and dead cells, respectively.
The number of total cells was calculated as the sum of viable and dead cells. The percent of viable cells were expressed as the ratio of the number of viable cells of each treatment group against those of control group. The percent of trypan blue positive cells were calculated using the following formula: the percent of trypan blue positive cells = the number of trypan blue positive cells/the number of total cells.

Growth inhibition assay. Cell growth inhibition by ATRA and/or VPA was investigated by XTT dye-reduction assays according to the method previously described with slight modifications (23). Briefly, the cells were seeded in 96-well plates (Iwaki, Tokyo, Japan) at a density of $1 \times 10^{4}$ cells per well in $0.1 \mathrm{ml}$ cell culture medium. Cultures in triplicate were treated with $1 \mu \mathrm{M}$ ATRA, $1 \mathrm{mM}$ VPA, alone or in combination. After 48 h of treatment, 2,3-bis(2-methoxy-4-nitro-5-sulfophenyl)5-[(phenylamino)carbonyl]-2 $\mathrm{H}$-tetrazolium hydroxide (XTT) (Sigma, MD, USA) and phenazine methosulfate (Wako Pure Chemical Industries, Osaka, Japan) were added into each well at final concentrations of $0.2 \mathrm{mg} / \mathrm{ml}$ and $1 \mathrm{mM}$, respectively. After incubation at $37^{\circ} \mathrm{C}$ for $2 \mathrm{~h}$, the plates were mixed, and the absorbance at $450 \mathrm{~nm}$ was measured with a microplate reader (Safire, Tecan, Switzerland). The relative cell viability was expressed as the ratio of the absorbance of each treatment group against those of the corresponding untreated control group.

Differentiation analysis. Differentiation induction was confirmed by morphology and expression of surface markers. For morphological assessment, cytospin preparations of treated cells stained with Wright-Giemsa were evaluated by light microscopy as previously described (24). Furthermore, the numbers of cells with differentiation-associated morphological changes such as apparent lobulated nuclei, multi-lobulated nuclei were counted and presented as the percent of differentiated cells. Myeloid maturation with cell surface marker was analyzed by FACSCanto flow cytometer (BD Immunocytometry System) using antibodies for CD11b and CD10 as previously described with minor modifications (24). In brief, approximately $1 \times 10^{6}$ cells were washed with PBS containing $2.5 \%$ FBS and $0.5 \% \mathrm{NaN}_{3}$ (PBSF) and stained with PE-conjugated mouse anti-human CD11b IgG or FITC-conjugated mouse anti-human CD10 $\mathrm{IgG}$ for $30 \mathrm{~min}$ at $4^{\circ} \mathrm{C}$ in the dark. Cells were then washed three times with PBSF and analyzed by flow cytometry with a minimum acquisition of 10,000 events. Non-binding mouse IgG-PE isotype antibody or non-binding mouse IgG-FITC isotype antibody was used as controls.

Expression profiles of transcription factors in NB4 cells. The expression levels of transcription factors, including $\mathrm{C} / \mathrm{EBP} \alpha$, $\mathrm{C} / \mathrm{EBP} \beta, \mathrm{C} / \mathrm{EBP} \varepsilon$ and PU.1 were evaluated by flow cytometry (Cyto ACE-150, Jasco) using antibody for each as previously described with minor modifications (24). In brief, approximately $1 \times 10^{6}$ cells were washed with PBS, and fixed with $4 \%$ formaldehyde for $10 \mathrm{~min}$ at $37^{\circ} \mathrm{C}$. Then, cells were permeabilized with $90 \%$ ice-cold methanol for over $2 \mathrm{~h}$ at $-20^{\circ} \mathrm{C}$. After washing with $\mathrm{PBS}$, cells were stained with primary antibodies against $\mathrm{C} / \mathrm{EBP} \alpha, \mathrm{C} / \mathrm{EBP} \beta, \mathrm{C} / \mathrm{EBP} \varepsilon$ and $\mathrm{PU} .1$ for $30 \mathrm{~min}$ at $4^{\circ} \mathrm{C}$, followed by staining with FITC-conjugated secondary 
antibody for $30 \mathrm{~min}$ at $4^{\circ} \mathrm{C}$ in the dark. Cells were then washed three times with PBS and analyzed by flow cytometry with a minimum acquisition of 10,000 events.

Western blot analysis. Protein samples were separated on an SDS-PAGE, followed by transferring to a nitrocellulose membrane as described previously (25). Proteins bands were detected using the following primary antibodies: rabbit polyclonal antibodies against human $\mathrm{C} / \mathrm{EBP} \alpha, \mathrm{C} / \mathrm{EBP} \beta, \mathrm{C} / \mathrm{EBP} \varepsilon$ and PU.1 (1:1,000 dilution). Blotted protein bands were detected with horseradish peroxidase-conjugated secondary antibody and an enhanced chemiluminescence (ECL) western blot analysis system (Amersham Pharmacia Biotech, Buckinghamshire, UK).

Statistical analysis. Experiments were independently repeated at least three times and results are shown as mean \pm standard deviation (SD). Data were analyzed using Student's t-test and $\mathrm{p}<0.05$ was considered as statistically significant.

\section{Results}

Cell viability of NB4 cells treated with ATRA and VPA, alone or in combination. Since $1 \mu \mathrm{M}$ ATRA has been commonly used to induce differentiation of NB4 cells $(16,18,26)$, the concentration was used in the current study to evaluate the differentiation-inducing activity of a combination of ATRA and VPA. In order to determine the appropriate concentration of VPA for the combinatorial treatment with $1 \mu \mathrm{M}$ ATRA, cell viability was first determined by trypan blue exclusion assay after treatment with $1 \mu \mathrm{M}$ ATRA and various concentrations of VPA $(0.1,0.3,1,3$ and $10 \mathrm{mM})$, alone or in combination, for $48 \mathrm{~h}$. No alteration was observed in the number of viable cells after treatment with $1 \mu \mathrm{M}$ ATRA and relatively low concentrations of VPA ( 0.1 and $0.3 \mathrm{mM})$, alone or in combination, as compared to control (Fig. 1A). A slight but not significant decrease in the number of viable cells was observed when NB4 cells were treated with $1 \mathrm{mM}$ VPA alone or in combination with $1 \mu \mathrm{M}$ ATRA (Fig. 1A). Furthermore, analysis of growth inhibition by the XTT dye-reduction assay demonstrated that treatment with $1 \mathrm{mM}$ VPA alone, instead of $1 \mu \mathrm{M}$ ATRA alone, significantly inhibited growth of NB4 cells, and that treatment with $1 \mathrm{mM}$ VPA in combination of $1 \mu \mathrm{M}$ ATRA further strengthened the growth inhibition as compared to each alone (Fig. 1C). On the other hand, treatment with relatively high concentrations of VPA ( 3 and $10 \mathrm{mM}$ ) alone or in combination with $1 \mu \mathrm{M}$ ATRA resulted in substantial decrease in the number of viable cells along with a marked increase in the number of trypan blue positive cells (Fig. 1A and B). Therefore, the concentrations of VPA ( 3 and $10 \mathrm{mM}$ ) were not used for further investigation of differentiation induction.

Differentiation of NB4 cell induction by ATRA and VPA, alone or in combination. NB4 cells have been demonstrated to differentiate toward granulocytic lineages after exposure to retinoic acid (19,27). Morphological changes such as condensation of chromatin, lobulation of nuclei, and increased expression of CD11b and CD10 have been used as markers of the differentiation of NB4 cells $(16,28-30)$. Therefore, the differentiation-inducing activity of $1 \mu \mathrm{M}$
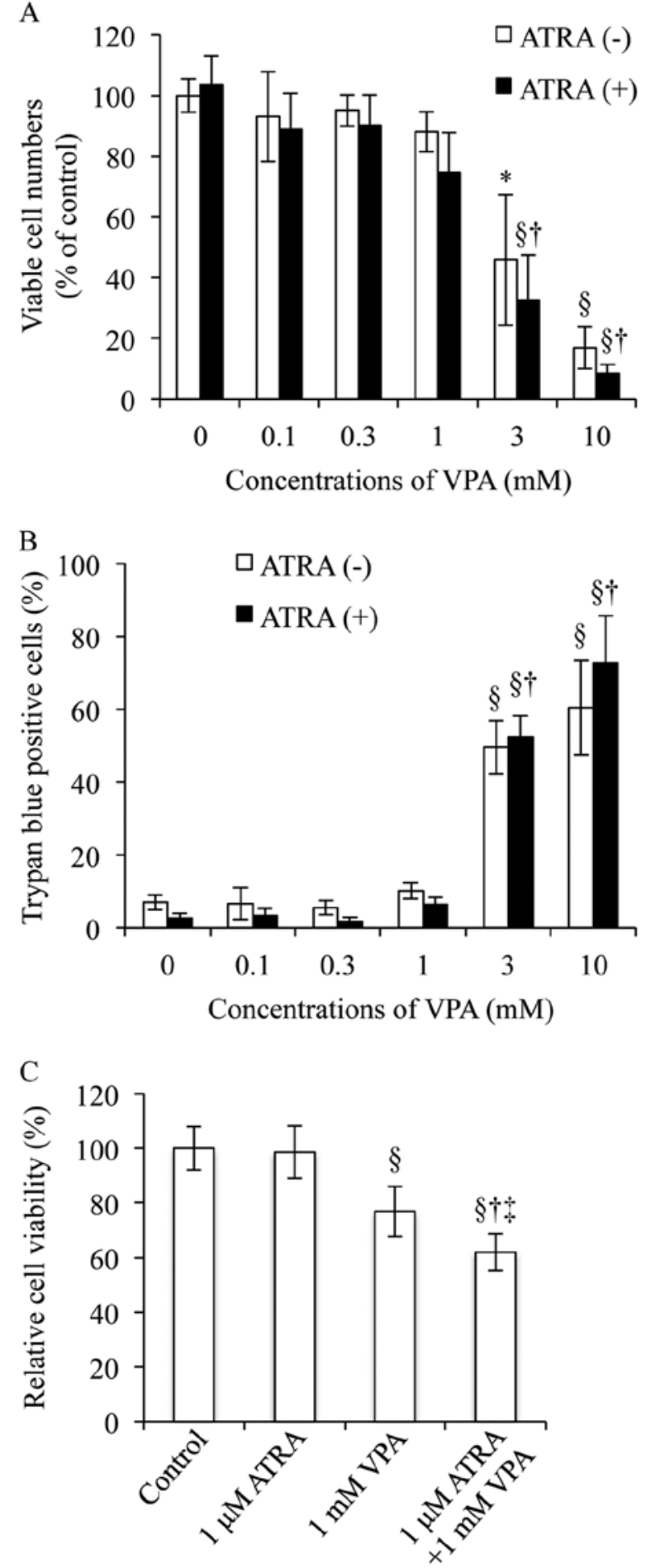

Figure 1. Cell viability of NB4 cells treated with ATRA and VPA, alone or in combination. After the treatment with $1 \mu \mathrm{M}$ ATRA and various concentrations of VPA $(0.1,0.3,1,3$ and $10 \mathrm{mM})$, alone or in combination, for $48 \mathrm{~h}$, cell viability [(A) viable cells, and (B) dead cells] and (C) growth inhibition were investigated by trypan blue exclusion assay and XTT dye-reduction assay, respectively, as described in Materials and methods. Experiments were independently repeated at least three times and results are shown as mean \pm SD. ${ }^{*} \mathrm{p}<0.05$ vs. control; ${ }^{\S} \mathrm{p}<0.01$ vs. control; ${ }^{\dagger} \mathrm{p}<0.01$ vs. $1 \mu \mathrm{M}$ ATRA; ${ }^{+}<0.01$ vs. VPA.

ATRA alone or in combination with various concentrations of VPA $(0.1,0.3$ and $1.0 \mathrm{mM})$ was first assessed by examining the alterations in CD11b expression level in NB4 cells. A 


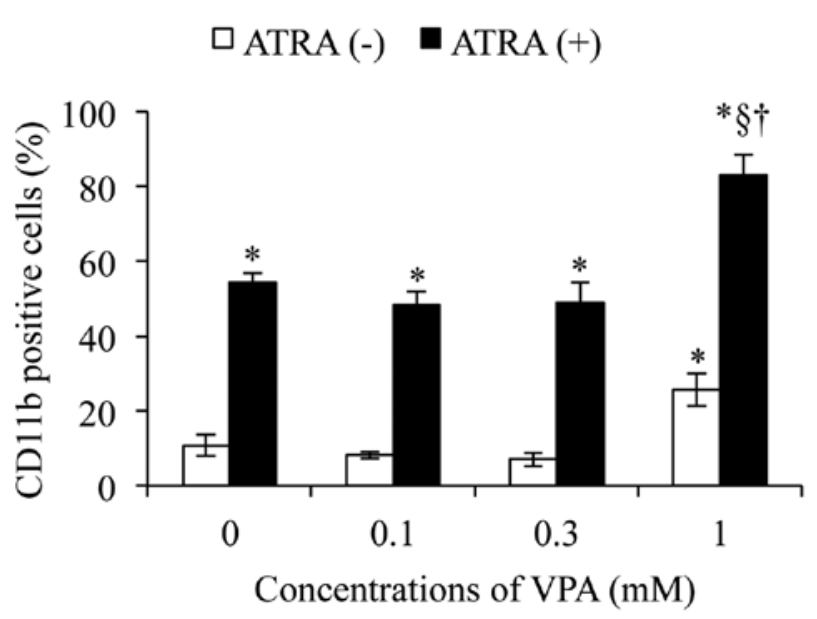

Figure 2. Expression profiles of CD11b in NB4 cells treated with ATRA and VPA, alone or in combination. After the treatment with $1 \mu \mathrm{M}$ ATRA and various concentrations of VPA $(0.1,0.3$ and $1 \mathrm{mM})$, alone or in combination, for $48 \mathrm{~h}$, alterations of the expression level of CD11b were evaluated by flow cytometry as described in Materials and methods. Experiments were independently repeated at least three times and results are shown as mean \pm SD. "p $<0.01$ vs. control; ${ }^{\circledR} \mathrm{p}<0.01$ vs. $1 \mu \mathrm{M}$ ATRA; ${ }^{\dagger} \mathrm{p}<0.01$ vs. $1 \mathrm{mM}$ VPA.

significant upregulation of the expression level of CD11b was observed in NB4 cells when treated with $1 \mathrm{mM}$ VPA alone, but not 0.1 and $0.3 \mathrm{mM}$ VPA alone, for $48 \mathrm{~h}$ (Fig. 2). Much higher level of CD11b expression was observed in NB4 cells treated with $1 \mu \mathrm{M}$ ATRA alone as compared to that observed when treated with $1 \mathrm{mM}$ VPA alone (Fig. 2). Furthermore, a significant increase in differentiation-inducing activity was observed only in NB4 cells treated with a combination of
$1 \mu \mathrm{M}$ ATRA and $1 \mathrm{mM}$ VPA when compared with the other two combinatorial treatment groups (Fig. 2). Therefore, the following experiments on morphological changes, the alterations in CD11b and CD10 expression levels were subsequently conducted by exposing NB4 cells to the combination of $1 \mu \mathrm{M}$ ATRA and $1 \mathrm{mM}$ VPA for $48 \mathrm{~h}$.

NB4 cells treated with $1 \mu \mathrm{M}$ ATRA alone underwent remarkable differentiation-associated changes with condensation and lobulation of nuclei (jelly bean-shaped nuclei, known as a stage before multi-lobulated nuclei) (control: $5.3 \pm 0.6$ vs. $1 \mu \mathrm{M}$ ATRA: $17.3 \pm 4.2, \mathrm{p}<0.01$ ) (Fig. 3 ), and a significant increase in $\mathrm{CD} 1 \mathrm{~b}$ expression concurred with the morphological changes (Fig. 4A and B). Treatment with $1 \mathrm{mM}$ VPA alone also induced significant morphological changes (control: $5.3 \pm 0.6$ vs. $1 \mathrm{mM}$ VPA: $16.3 \pm 2.5$, p $<0.01$ ) (Fig. 3 ) and upregulation of CD11b expression levels (Fig. 4A and B). Furthermore, the number of cells containing multi-lobulated nuclei prominently increased when the cells were treated with the combination of ATRA and VPA as compared to that treated with each alone ( $1 \mu \mathrm{M}$ ATRA: $17.3 \pm 4.2 ; 1 \mathrm{mM}$ VPA: $16.3 \pm 2.5$ vs. $1 \mu \mathrm{M}$ ATRA $+1 \mathrm{mM}$ VPA: $57.7 \pm 1.2, \mathrm{p}<0.01$ ) (Fig. 3). The increase in differentiation-inducing activities due to combination treatment was further confirmed by a significant increase in CD11b and CD10 expression level as compared to each alone (Fig. 4).

Expression profiles of C/EBPs and PU.1 in NB4 cells treated with ATRA and VPA, alone or in combination. After the treatment with $1 \mu \mathrm{M}$ ATRA and $1 \mathrm{mM} \mathrm{VPA}$, alone or in combination, for $48 \mathrm{~h}$, the expression levels of C/EBPs and PU.1 were evaluated using FACS and western blot analysis. ATRA alone significantly upregulated $\mathrm{C} / \mathrm{EBP} \beta$ and $\varepsilon$, whereas VPA

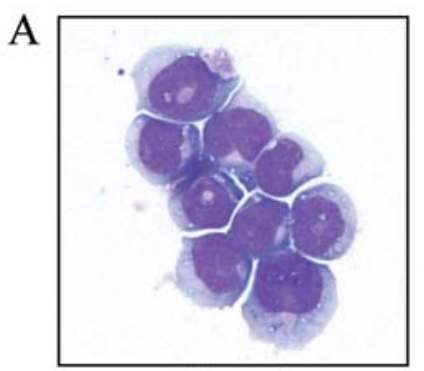

Control

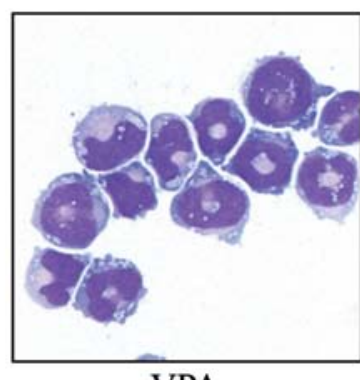

VPA

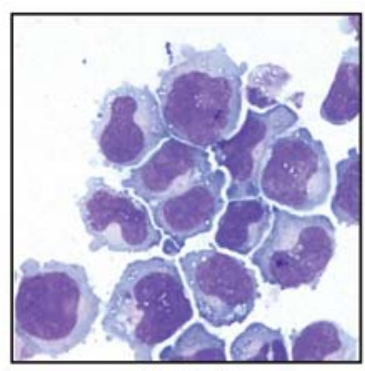

ATRA

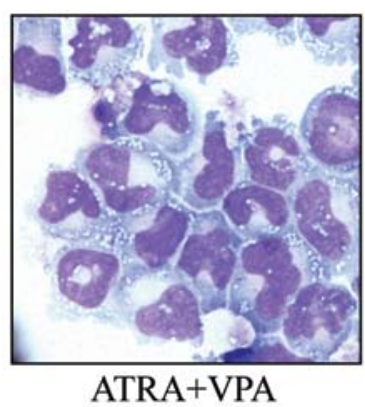

B

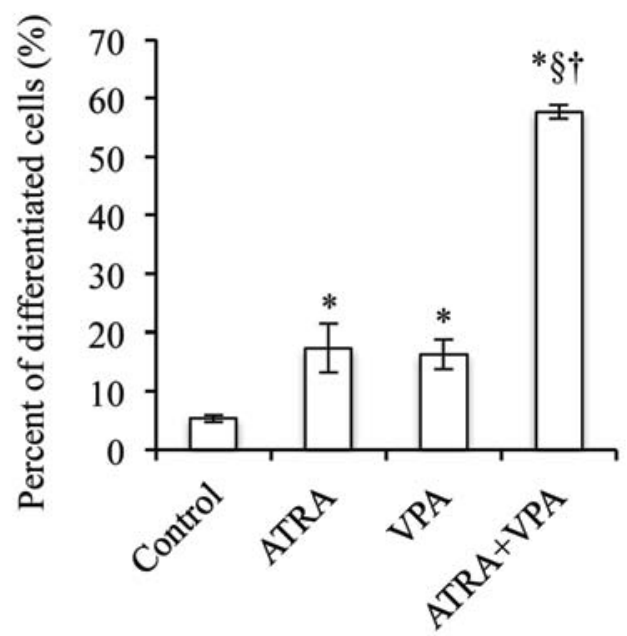

Figure 3. Morphological changes in NB4 cells treated with ATRA and VPA, alone or in combination. After the treatment with $1 \mu$ M ATRA and 1 mM VPA, alone or in combination, for $48 \mathrm{~h}$, morphological changes were evaluated by Wright-Giemsa staining as described in Materials and methods. (A) Representative photomicrographs are shown from three independent experiments. (B) The number of cells with apparent lobulated nuclei and multi-lobulated nuclei were counted and presented. Experiments were independently repeated at least three times and results are shown as mean \pm SD. ${ }^{*}$ p $<0.01$ vs. control; ${ }^{\S} \mathrm{p}<0.001 \mathrm{vs}$. ATRA; ${ }^{\dagger} \mathrm{p}<0.001$ vs. VPA). 

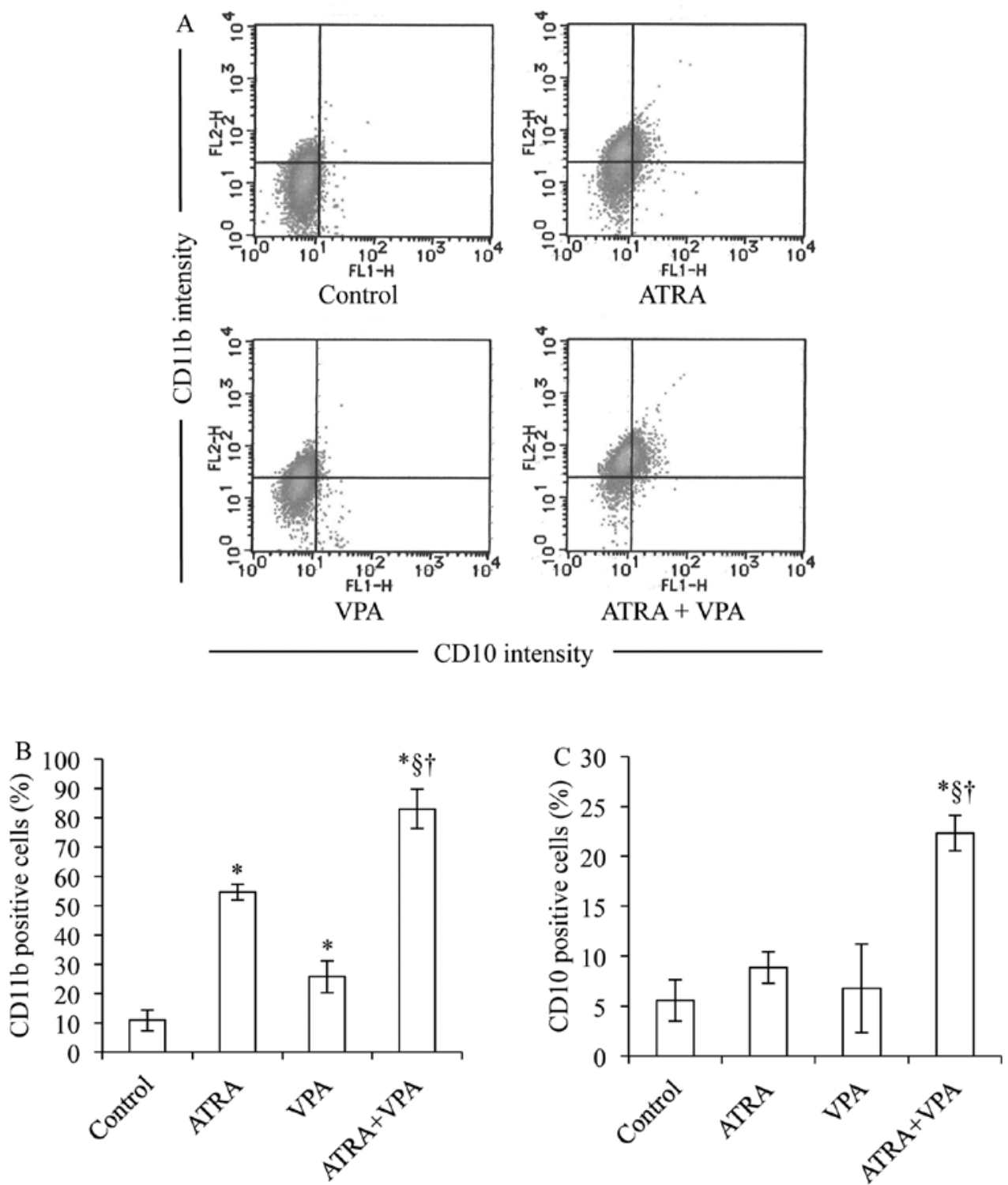

Figure 4. Expression profiles of CD11b and CD10 in NB4 cells treated with ATRA and VPA, alone or in combination. After treatment with $1 \mu \mathrm{M}$ ATRA and $1 \mathrm{mM}$ VPA, alone or in combination, for $48 \mathrm{~h}$, alterations of the expression level of CD11b and CD10 were evaluated by flow cytometry as described in Materials and methods. (A) Flow cytometry profiles of CD11b and CD10. (B and C) Percent of CD11b and CD10 positive cells were calculated, respectively, based on flow cytometry profiles shown in (A). Experiments were independently repeated at least three times and results are shown as mean \pm SD). ${ }^{*} \mathrm{p}<0.001 \mathrm{vs}$. control; ${ }^{\S} \mathrm{p}<0.05$ vs. ATRA; ${ }^{\dagger} \mathrm{p}<0.001$ vs. VPA.

alone significantly upregulated $\mathrm{C} / \mathrm{EBP} \alpha, \beta$ and $\varepsilon$ (Figs. 5-7). Of note, the degree of upregulation in $\mathrm{C} / \mathrm{EBP} \beta$ and $\varepsilon$ induced by ATRA and VPA is almost the same (Figs. 6 and 7). It is of note that both ATRA and VPA significantly upregulated PU.1 expression (Fig. 8). Furthermore, combinational treatment of ATRA and VPA significantly upregulated the expression level of $\mathrm{C} / \mathrm{EBP} \alpha, \beta, \varepsilon$ and PU.1 as compared to that treated with each alone (Figs. 5-8). Moreover, the expression levels of these transcription factors demonstrated by western blot analysis are in good agreement with those demonstrated by FACS analysis (Fig. 9).

\section{Discussion}

It has been demonstrated that VPA inhibits the growth of NB4, HL-60 and U937 cells by causing cell cycle arrest at
$\mathrm{G}_{0} / \mathrm{G}_{1}$ phase (12). VPA has also been demonstrated to induce apoptosis in other human leukemia cells by stimulating both caspase-dependent and -independent apoptotic signaling pathways $(12,31)$. In the current study, we first demonstrated that a slight but not significant decrease in the number of viable cells was observed when NB4 cells were treated with $1 \mathrm{mM}$ VPA alone or in combination with $1 \mu \mathrm{M}$ ATRA (Fig. 1A). We further demonstrated that a significant growth inhibition was observed after treatment with $1 \mathrm{mM}$ VPA, and that the growth inhibition was strengthened by the addition of $1 \mu \mathrm{M}$ ATRA (Fig. 1C). Furthermore, no alteration in the number of trypan blue positive cells was observed in the same treatment, whereas treatment with relatively high concentrations of VPA ( 3 and $10 \mathrm{mM}$ ) alone or in combination with $1 \mu \mathrm{M}$ ATRA resulted in substantial increase in the number of trypan blue positive cells (Fig. 1B). Taken together, results suggest 


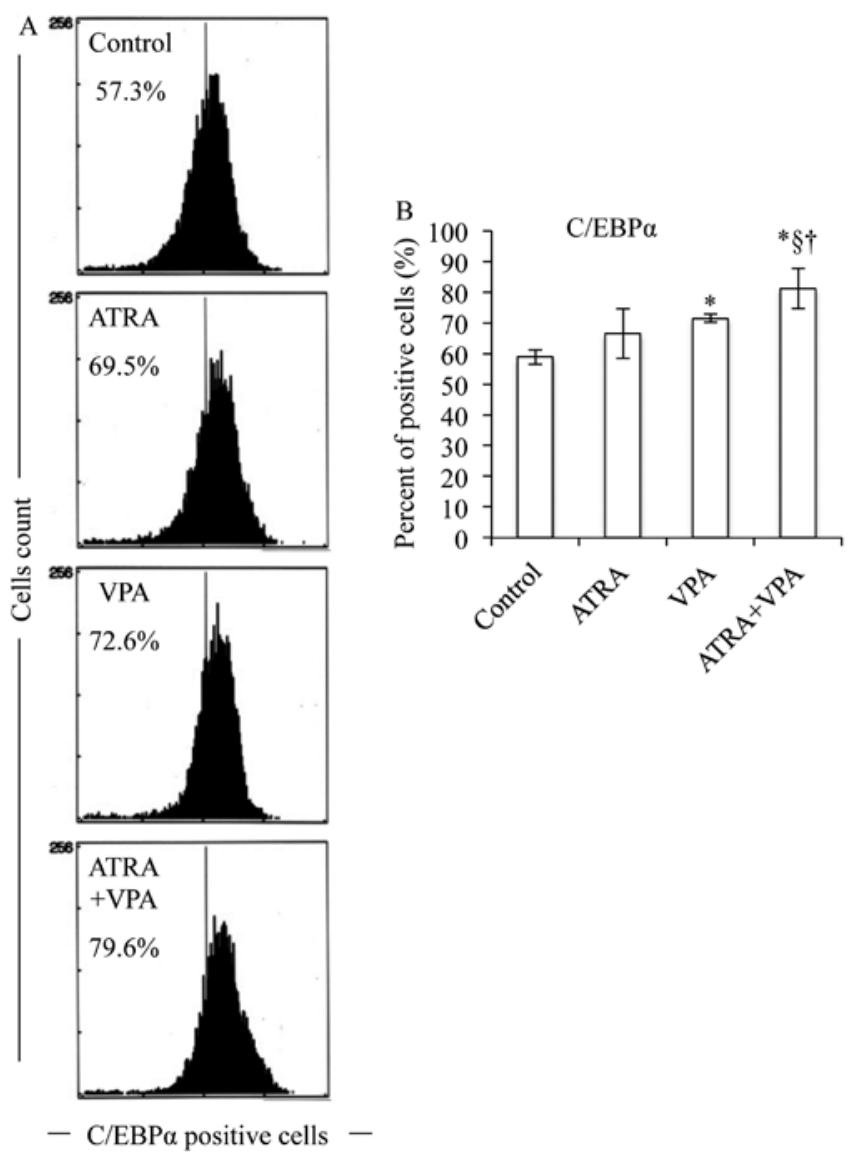

Figure 5. Flow cytometry analysis of $\mathrm{C} / \mathrm{EBP} \alpha$ in NB4 cells treated with ATRA and VPA, alone or in combination. After the treatment with $1 \mu \mathrm{M}$ ATRA and $1 \mathrm{mM}$ VPA, alone or in combination, for $48 \mathrm{~h}$, alterations of the expression level of $\mathrm{C} / \mathrm{EBP} \alpha$ were evaluated by flow cytometry as described in Materials and methods. (A) Flow cytometry profiles of C/EBP $\alpha$. (B) Percent of $\mathrm{C} / \mathrm{EBP} \alpha$ positive cells were calculated based on flow cytometry profiles shown in (A). Experiments were independently repeated at least three times and results are shown as mean \pm SD. ${ }^{*} \mathrm{p}<0.01$ vs. control; ${ }^{\circledR} \mathrm{p}<0.05$ vs. ATRA; ${ }^{\dagger} \mathrm{p}<0.05$ vs. VPA).

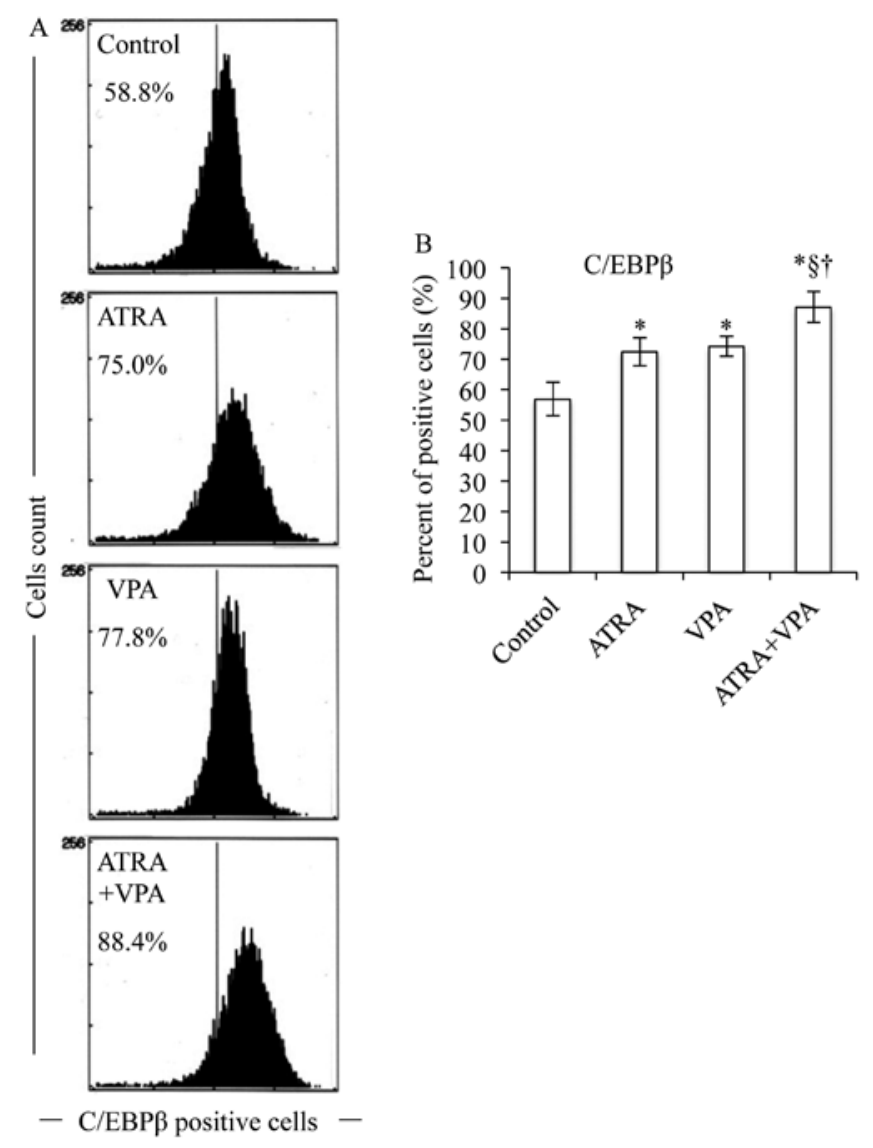

Figure 6. Flow cytometry analysis of $\mathrm{C} / \mathrm{EBP} \beta$ in NB4 cells treated with ATRA and VPA, alone or in combination. After the treatment with $1 \mu \mathrm{M}$ ATRA and $1 \mathrm{mM}$ VPA, alone or in combination, for $48 \mathrm{~h}$, alterations of the expression level of $\mathrm{C} / \mathrm{EBP} \beta$ were evaluated by flow cytometry as described in Materials and methods. (A) Flow cytometer profiles of C/EBP $\beta$. (B) Percent of $\mathrm{C} / \mathrm{EBP} \beta$ positive cells were calculated based on flow cytometry profiles shown in (A). Experiments were independently repeated at least three times and results are shown as mean \pm SD. ${ }^{*} \mathrm{p}<0.01$ vs. control; ${ }^{\S} \mathrm{p}<0.05$ vs. ATRA; ${ }^{\dagger} \mathrm{p}<0.05 \mathrm{vs}$. VPA. that proliferation arrest, rather than apoptosis, is a plausible mechanism responsible for the growth inhibition induced by VPA or VPA/ATRA. Furthermore, it is possible that ATRA-mediated differentiation contributes to the enhancement of the growth inhibition, although further investigation is still needed to draw a concrete conclusion.

Next, we demonstrated that not only ATRA but also VPA induced differentiation in NB4 cells (Figs. 2-4). The combination of ATRA and VPA further augmented the differentiation activity as compared to that treated with each alone. Similar to our results, a previous report demonstrated that VPA induced differentiation in not only NB4 cells but also HL-60 and U937 cells, although there were some differences in the degree of differentiation among these leukemia cells (12). Kosugi et al has also demonstrated that trichostatin A, another HDACi, synergistically induced differentiation in NB4 and HL-60 cells as well as their ATRA-resistant sublines in combination with ATRA (26). Furthermore, it has been demonstrated that VPA per se induced differentiation in PML-RAR $\alpha$ and promyelocytic leukemia zinc-finger protein (PLZF)-RAR $\alpha$-transformed mouse hematopoietic progenitor cells, and enhances ATRA-induced differen- tiation in these cells (32). These findings thus suggest that differentiation-inducing activities of these reagents do not appear to be associated with a specific cytogenetic subtype of AML, and that a larger scale study must be launched in order to draw a solid conclusion.

We further demonstrated that treatment with ATRA alone resulted in the upregulation of $\mathrm{C} / \mathrm{EBP}(\beta, \varepsilon)$, but not $\mathrm{C} / \mathrm{EBP} \alpha$ in NB4 cells (Figs. 5-7), suggesting that $\mathrm{C} / \mathrm{EBP}(\beta, \varepsilon)$ play more critical roles in the ATRA-induced differentiation. The notion was supported by several previous reports showing that ATRA-induced differentiation of APL cells might be mediated by $\mathrm{C} / \mathrm{EBP}$ factors, most notably $\mathrm{C} / \mathrm{EBP} \beta$ and $\mathrm{C} /$ EBPe $(19,22)$. Indeed, electrophoretic mobility shift assay of nuclear extract from NB4 cells after ATRA stimulation revealed an increase in the binding activity of $\operatorname{C} / \operatorname{EBP}(\beta, \varepsilon)$, but not that of $\mathrm{C} / \mathrm{EBP} \alpha$ (16). Interestingly, VPA alone significantly upregulated $\mathrm{C} / \operatorname{EBP}(\alpha, \beta, \varepsilon)$ expression levels (Figs. 5-7). Data are scarce on whether C/EBPs or PU.1 are involved in VPA-induced differentiation of NB4 cells (PML-RAR $\alpha$ positive), although a considerable amount of studies dealing with the differentiation-inducing activity of VPA in non-APL HL-60 cells (PML-RAR $\alpha$ negative) has 


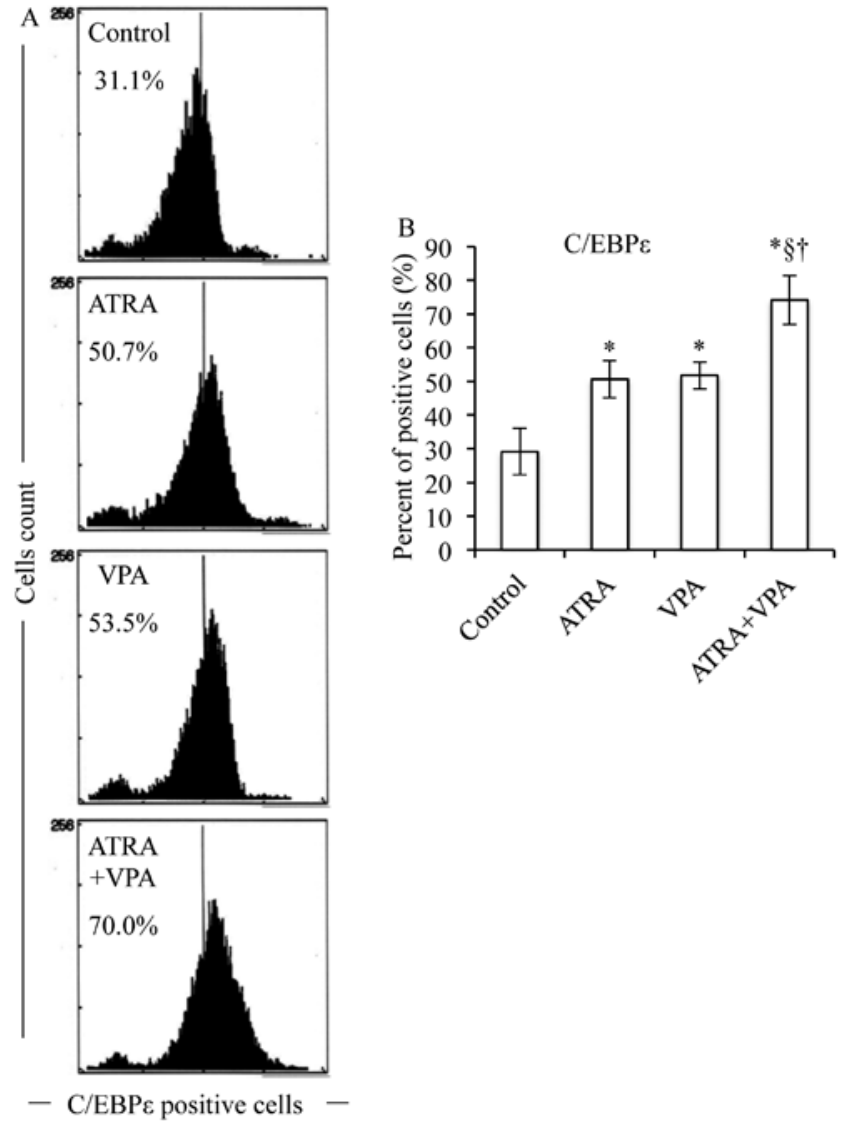

Figure 7. Flow cytometry analysis of C/EBPe in NB4 cells treated with ATRA and VPA, alone or in combination. After the treatment with $1 \mu \mathrm{M}$ ATRA and $1 \mathrm{mM}$ VPA, alone or in combination, for $48 \mathrm{~h}$, alterations of the expression level of $\mathrm{C} / \mathrm{EBP} \varepsilon$ were evaluated by flow cytometry as described in Materials and methods. (A) Flow cytometry profiles of C/EBPE. (B) Percent of C/EBP positive cells were calculated based on flow cytometer profiles shown in (A). Experiments were independently repeated at least three times and results are shown as mean \pm SD. ${ }^{*} \mathrm{p}<0.01$ vs. control; ${ }^{\circledR} \mathrm{p}<0.01$ vs. ATRA; ${ }^{\dagger} \mathrm{p}<0.01 \mathrm{vs.} \mathrm{VPA}$

been conducted $(12,26,33)$. To the best of our knowledge, this is the first report to demonstrate the effects of VPA on the PML-RAR $\alpha$ positive APL cells by focusing on differentiation associated with the expression of transcription factors, C/EBPs and PU.1.

We also demonstrated that both ATRA and VPA significantly induced PU.1 expression level (Fig. 8). It has been demonstrated that ATRA resolves the differentiation block in APL cell lines and primary blasts by restoring PU.1 expression (18). Furthermore, ATRA-induced activation of PU.1 in these cells is mediated by upregulation of the C/EBPs, especially C/EBP $\beta$ (18). In agreement with our results, Zapotocky et al also demonstrated that VPA increased the expression of PU.1, resulting in differentiation induction in $\mathrm{t}(8 ; 21) / \mathrm{AML1}$-ETO-positive leukemic cells (34). More importantly, we further demonstrated that combination treatment with ATRA and VPA resulted in the upregulation of $\mathrm{C} / \mathrm{EBP}(\alpha, \beta, \varepsilon)$ and PU.1 (Figs. 5-8) as compared to that treated with each alone, suggesting that synergistic or additive effects of these reagents on differentiation induction are attributed to the restoration of the normal function of the myeloid cell transcriptional machinery. Given the importance of $\mathrm{C} /$

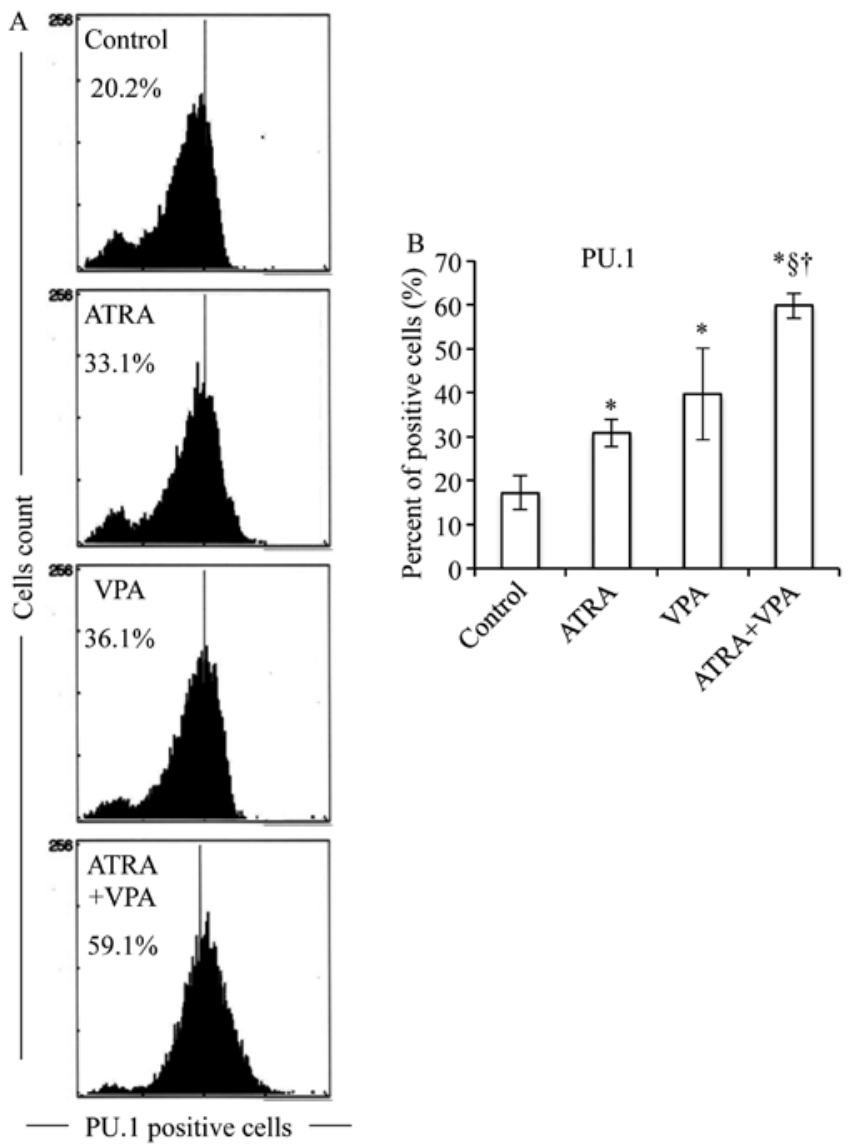

Figure 8. Flow cytometry analysis of PU.1 in NB4 cells treated with ATRA and VPA, alone or in combination. After treatment with $1 \mu \mathrm{M}$ ATRA and $1 \mathrm{mM}$ VPA, alone or in combination, for $48 \mathrm{~h}$, alterations of the expression level of PU.1 were evaluated by flow cytometry as described in Materials and methods. (A) Flow cytometry profiles of PU.1. (B) Percent of PU.1 positive cells were calculated based on flow cytometry profiles shown in (A). Experiments were independently repeated at least three times and results are shown as mean \pm SD. ${ }^{*} \mathrm{p}<0.01$ vs. control; ${ }^{\S} \mathrm{p}<0.001$ vs. ATRA; ${ }^{\dagger} \mathrm{p}<0.01$ vs. VPA).

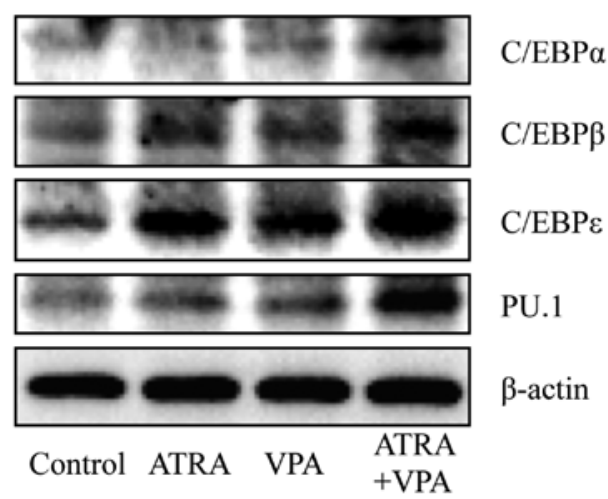

Figure 9. Western blot analysis of C/EBPs and PU.1 protein expression levels in NB4 cells treated with ATRA and VPA, alone or in combination. After the treatment with $1 \mu \mathrm{M}$ ATRA and $1 \mathrm{mM}$ VPA, alone or in combination, for $48 \mathrm{~h}$, the expression profiles of $\mathrm{C} / \mathrm{EBP}(\alpha, \beta, \varepsilon), \mathrm{PU} .1$ and $\beta$-actin proteins were evaluated by western blot analysis as described in Materials and methods.

$\operatorname{EBP}(\alpha, \beta, \varepsilon)$ and PU.1 in myeloid development, these studies suggest that restoring the expression of these transcriptional factors may represent a possible therapeutic modality leading 
to differentiation of APL cells. Therefore, efforts to clarify the potential clinical significance of the combination of ATRA and VPA in patients with not only non-APL AML and MDS but also APL are warranted.

In conclusion, our findings demonstrating growth inhibition, enhanced differentiation and upregulation of transcription factors in NB4 cells treated with combination of VPA and ATRA provide novel insight into a possible combinational therapeutic approach to APL patients. It has been suggested that ATO/ATRA degrade PML-RAR $\alpha$ oncoprotein, resulting in eradication of leukemia-initiating cells $(32,35,36)$. Therefore, as a new therapeutic approach, a multi-target therapy based on a combination of ATRA, ATO and VPA would be useful and worth evaluating further for its beneficial clinical effects.

\section{Acknowledgements}

The authors thank Mr.Fumitaka Takemae and Ms. Eiko Ishizuka for their technical assistance. This study was supported in part by grants from the Ministry of Education, Culture, Sports, Science and Technology and by the Promotion and Mutual Aid Corporation for Private Schools of Japan.

\section{References}

1. Grignani F, De Matteis S, Nervi C, Tomassoni L, Gelmetti V, Cioce M, Fanelli M, Ruthardt M, Ferrara FF, Zamir I, Seiser C, Grignani F, Lazar MA, Minucci S and Pelicci PG: Fusion proteins of the retinoic acid receptor-alpha recruit histone deacetylase in promyelocytic leukaemia. Nature 391: 815-818, 1998.

2. Lin RJ, Nagy L, Inoue S, Shao W, Miller WH Jr and Evans RM: Role of the histone deacetylase complex in acute promyelocytic leukaemia. Nature 391: 811-814, 1998.

3. Fang J, Chen SJ, Tong JH, Wang ZG, Chen GQ and Chen Z: Treatment of acute promyelocytic leukemia with ATRA and As2O3: a model of molecular target-based cancer therapy. Cancer Biol Ther 1: 614-620, 2002.

4. Wang ZY and Chen Z: Acute promyelocytic leukemia: from highly fatal to highly curable. Blood 111: 2505-2515, 2008.

5. Zhang JW, Wang JY, Chen SJ and Chen Z: Mechanisms of all-trans retinoic acid-induced differentiation of acute promyelocytic leukemia cells. J Biosci 25: 275-284, 2000.

6. Melnick A and Licht JD: Deconstructing a disease: RARalpha, its fusion partners, and their roles in the pathogenesis of acute promyelocytic leukemia. Blood 93: 3167-3215, 1999.

7. Tallman MS and Altman JK: Curative strategies in acute promyelocytic leukemia. Hematology Am Soc Hematol Educ Program 1: 391-399, 2008.

8. Thirugnanam R, George B, Chendamarai E, Lakshmi KM, Balasubramanian P, Viswabandya A, Srivastava A, Chandy M and Mathews V: Comparison of clinical outcomes of patients with relapsed acute promyelocytic leukemia induced with arsenic trioxide and consolidated with either an autologous stem cell transplant or an arsenic trioxide-based regimen. Biol Blood Marrow Transplant 15: 1479-1484, 2009.

9. Göttlicher M, Minucci S, Zhu P, Krämer OH, Schimpf A, Giavara S, Sleeman JP, Lo Coco F, Nervi C, Pelicci PG and Heinzel T: Valproic acid defines a novel class of HDAC inhibitors inducing differentiation of transformed cells. EMBO J 20: 6969-6978, 2001.

10. Quintás-Cardama A, Santos FP and Garcia-Manero G: Histone deacetylase inhibitors for the treatment of myelodysplastic syndrome and acute myeloid leukemia. Leukemia 25: 226-235, 2011.

11. Bolden JE, Peart MJ and Johnstone RW: Anticancer activities of histone deacetylase inhibitors. Nat Rev Drug Discov 5: 769-784, 2006.

12. Cheng YC, Lin H, Huang MJ, Chow JM, Lin S and Liu HE: Downregulation of c-Myc is critical for valproic acid-induced growth arrest and myeloid differentiation of acute myeloid leukemia. Leuk Res 31: 1403-1411, 2007.
13. Cimino G, Lo-Coco F, Fenu S, Travaglini L, Finolezzi E, Mancini M, Nanni M, Careddu A, Fazi F, Padula F, Fiorini R, Spiriti MA, Petti MC, Venditti A, Amadori S, Mandelli F, Pelicci PG and Nervi C: Sequential valproic acid/all-trans retinoic acid treatment reprograms differentiation in refractory and high-risk acute myeloid leukemia. Cancer Res 66: 8903-8911, 2006.

14. Kuendgen A, Schmid M, Schlenk R, Knipp S, Hildebrandt B, Steidl C, Germing U, Haas R, Dohner H and Gattermann N: The histone deacetylase (HDAC) inhibitor valproic acid as monotherapy or in combination with all-trans retinoic acid in patients with acute myeloid leukemia. Cancer 106: 112-119, 2006.

15. Kuendgen A, Strupp C, Aivado M, Bernhardt A, Hildebrandt B, Haas R, Germing U and Gattermann N: Treatment of myelodysplastic syndromes with valproic acid alone or in combination with all-trans retinoic acid. Blood 104: 1266-1269, 2004.

16. Duprez E, Wagner K, Koch H and Tenen DG: C/EBPbeta: a major PML-RARA-responsive gene in retinoic acid-induced differentiation of APL cells. EMBO J 22: 5806-5816, 2003.

17. Guibal FC, Alberich-Jorda M, Hirai H, Ebralidze A, Levantini E, Di Ruscio A, Zhang P, Santana-Lemos BA, Neuberg D, Wagers AJ, Rego EM and Tenen DG: Identification of a myeloid committed progenitor as the cancer-initiating cell in acute promyelocytic leukemia. Blood 114: 5415-5425, 2009.

18. Mueller BU, Pabst T, Fos J, Petkovic V, Fey MF, Asou N, Buergi $U$ and Tenen DG: ATRA resolves the differentiation block in $\mathrm{t}(15 ; 17)$ acute myeloid leukemia by restoring PU.1 expression. Blood 107: 3330-3338, 2006.

19. Park DJ, Chumakov AM, Vuong PT, Chih DY, Gombart AF, Miller WH Jr and Koeffler HP: CCAAT/enhancer binding protein epsilon is a potential retinoid target gene in acute promyelocytic leukemia treatment. J Clin Invest 103: 1399-1408, 1999.

20. Rosmarin AG, Yang Z and Res es KK: Transcriptional regulation in myelopoiesis: Hematopoietic fate choice, myeloid differentiation, and leukemogenesis. Exp Hematol 33: 131-143, 2005.

21. Zhang K, Li J, Meng W, Xing H and Yang Y: C/EBPbeta and CHOP participate in tanshinone IIA-induced differentiation and apoptosis of acute promyelocytic leukemia cells in vitro. Int J Hematol 92: 571-578, 2010.

22. Tenen DG: Disruption of differentiation in human cancer: AML shows the way. Nat Rev Cancer 3: 89-101, 2003.

23. Yoshino Y, Yuan B, Kaise T, Takeichi M, Tanaka S, Hirano T, Kroetz DL and Toyoda H: Contribution of aquaporin 9 and multidrug resistance-associated protein 2 to differential sensitivity to arsenite between primary cultured chorion and amnion cells prepared from human fetal membranes. Toxicol Appl Pharmacol 257: 198-208, 2011.

24. Iriyama N, Yuan B, Hatta Y, Horikoshi A, Yoshino Y, Toyoda H, Aizawa $S$ and Takeuchi J: Granulocyte colony-stimulating factor potentiates differentiation induction by all-trans retinoic acid and arsenic trioxide and enhances arsenic uptake in the acute promyelocytic leukemia cell line HT93A. Oncol Rep 28: 1875-1882, 2012.

25. Yuan B, Ohyama K, Takeichi M and Toyoda H: Direct contribution of inducible nitric oxide synthase expression to apoptosis induction in primary smooth chorion trophoblast cells of human fetal membrane tissues. Int J Biochem Cell Biol 41: 1062-1069, 2009.

26. Kosugi H, Towatari M, Hatano S, Kitamura K, Kiyoi H, Kinoshita T, Tanimoto M, Murate T, Kawashima K, Saito H and Naoe T: Histone deacetylase inhibitors are the potent inducer/enhancer of differentiation in acute myeloid leukemia: a new approach to anti-leukemia therapy. Leukemia 13: 1316-1324, 1999.

27. Morosetti R, Park DJ, Chumakov AM, Grillier I, Shiohara M, Gombart AF, Nakamaki T, Weinberg K and Koeffler HP: A novel, myeloid transcription factor, C/EBP epsilon, is upregulated during granulocytic, but not monocytic, differentiation. Blood 90: 2591-2600, 1997.

28. Inazawa Y, Saeki K and Yuo A: Granulocyte colony-stimulating factor-induced terminal maturation of human myeloid cells is specifically associated with up-regulation of receptor-mediated function and CD10 expression. Int J Hematol 77: 142-151, 2003.

29. Zhao Q, Tao J, Zhu Q, Jia PM, Dou AX, Li X, Cheng F, Waxman S, Chen GQ, Chen SJ, Lanotte M, Chen Z and Tong JH: Rapid induction of cAMP/PKA pathway during retinoic acid-induced acute promyelocytic leukemia cell differentiation. Leukemia 18: 285-292, 2004. 
30. Zhang K, Guo QL, You QD, Yang Y, Zhang HW, Yang L, Gu HY, Qi Q, Tan Z and Wang X: Wogonin induces the granulocytic differentiation of human NB4 promyelocytic leukemia cells and up-regulates phospholipid scramblase 1 gene expression. Cancer Sci 99: 689-695, 2008.

31. Kawagoe R, Kawagoe H and Sano K: Valproic acid induces apoptosis in human leukemia cells by stimulating both caspase-dependent and -independent apoptotic signaling pathways. Leuk Res 26: 495-502, 2002.

32. Leiva M, Moretti S, Soilihi H, Pallavicini I, Peres L, Mercurio C, Dal Zuffo R, Minucci S and de Thé H: Valproic acid induces differentiation and transient tumor regression, but spares leukemia-initiating activity in mouse models of APL. Leukemia 26: 1630-1637, 2012.

33. Deubzer H, Busche B, Rönndahl G, Eikel D, Michaelis M, Cinatl J, Schulze S, Nau $\mathrm{H}$ and Witt O: Novel valproic acid derivatives with potent differentiation-inducing activity in myeloid leukemia cells. Leuk Res 30: 1167-1175, 2006.
34. Zapotocky M, Mejstrikova E, Smetana K, Stary J, Trka J and Starkova J: Valproic acid triggers differentiation and apoptosis in AML1/ETO-positive leukemic cells specifically. Cancer Lett 319: 144-153, 2012.

35. Ito K, Bernardi R, Morotti A, Matsuoka S, Saglio G, Ikeda Y, Rosenblatt J, Avigan DE, Teruya-Feldstein J and Pandolfi PP: PML targeting eradicates quiescent leukaemia-initiating cells. Nature 453: 1072-1078, 2008

36. Yuan B, Yoshino Y, Kaise T and Toyoda H: Application of arsenic trioxide therapy for patients with leukemia. In: Biological Chemistry of Arsenic, Antimony and Bismuth. Sun H (ed). John Wiley \& Sons, Ltd., Chichester, pp263-292, 2011. 